\title{
Contribution of gas adsorption-desorption in Marcellus shale for different fractured well configurations
}

\author{
Temoor Muther $^{1}\left[\right.$ D Fahad Iqbal Syed ${ }^{1} \cdot$ Amirmasoud Kalantari Dahaghi $^{1} \cdot$ Shahin Negahban $^{1}$
}

Received: 14 July 2021 / Accepted: 3 January 2022 / Published online: 17 January 2022

(c) The Author(s) 2022

\begin{abstract}
Gas adsorption onto the shale system carries significant importance in accurately forecasting gas production and estimating underground reserves. For the Marcellus shale system, the adsorption of gas also plays a critical role in ultimate recovery and overall reserves quantification. Yet, the effect of different adsorption characteristics in different Marcellus shale regions is not systematically analyzed together. In this study, the contribution of different gas adsorption phenomena in Marcellus shale for different fractured well configurations is investigated. The objective is to understand the reservoir production responses under various adsorption characteristics and well design. For this analysis, a mechanistic Marcellus shale model under confining stresses is numerically simulated with the available literature data. After that, six samples containing adsorption characteristics of different Marcellus shale regions are taken from the literature and specified in the model for accurately defining the adsorption physics in the shale system. In the end, two different well configurations including the fractured vertical and horizontal well are specified in the model separately to analyze the impact of gas desorption on production response. The analysis indicates that the gas desorption improves the overall gas production by a maximum of 5\% in a single-stage multiclustered fractured horizontal well. In addition, the effect of desorption is found to be minimal during initial flow periods, and considerable at longer flow periods. Additionally, the gas desorption is found to be more responsive towards high surface area and large fracture networks. Finally, it is determined that a fractured horizontal well is a viable option that allows high gas desorption in Marcellus shale. This study, hence, aids widely in deciding better production strategies based on adsorption characteristics for producing Marcellus shale.
\end{abstract}

Keywords Gas adsorption · Marcellus shale $\cdot$ Hydraulic fracture $\cdot$ Well configuration · Confining stress

\section{Introduction}

The shale reservoirs are gaining significant attention over the past few decades because of their large hydrocarbon resources worldwide. Such reservoirs have a prominent characteristic of behaving both as a reservoir and source rock (Gomaa et al. 2014; Yu and Sepehrnoori 2014a). Out of many shale resources, Marcellus shale (a Devonian black shale) is one of the significant gas producers in the United States (refer to Fig. 1). It is located in the Appalachian Basin and spread across Pennsylvania, Ohio, New York, Maryland, Virginia,

Temoor Muther

temoormuther@ku.edu

$\triangle$ Amirmasoud Kalantari Dahaghi

masoud@ku.edu

1 Department of Chemical and Petroleum Engineering, University of Kansas, Lawrence, KS, USA and West Virginia (Bartuska et al. 2012; Yildirim et al. 2019; $\mathrm{Yu}$ and Sepehrnoori 2014b). This resource has a total area of 100,000 miles $^{2}$, the thickness in the range of 50-200 ft, and the depth is around 4000-8500 ft. The total organic content (TOC) of this resource is between 5 and $30 \%$ with the average porosity in the range of 6-8\% (Glorioso and Rattia 2012; Yu and Sepehrnoori 2014b). In addition, the reservoir temperature of Marcellus shale is about $140{ }^{\circ} \mathrm{F}$ with bottom-hole pressure extending up to $6000 \mathrm{psi}$. The original gas in place (OGIP) and the technically recoverable gas of this resource are about 1500 TCF and 141 TCF respectively (Yu and Sepehrnoori 2014b).

Geologically, the shale gas in the rock matrix exists as the:

a. Adsorbed gas onto the kerogen and rock surface

b. Free gas in the natural fractures and rock structure

This adsorbed and free gas highly contribute to the recovery potential of these resources (Holditch et al. 2007). Generally 


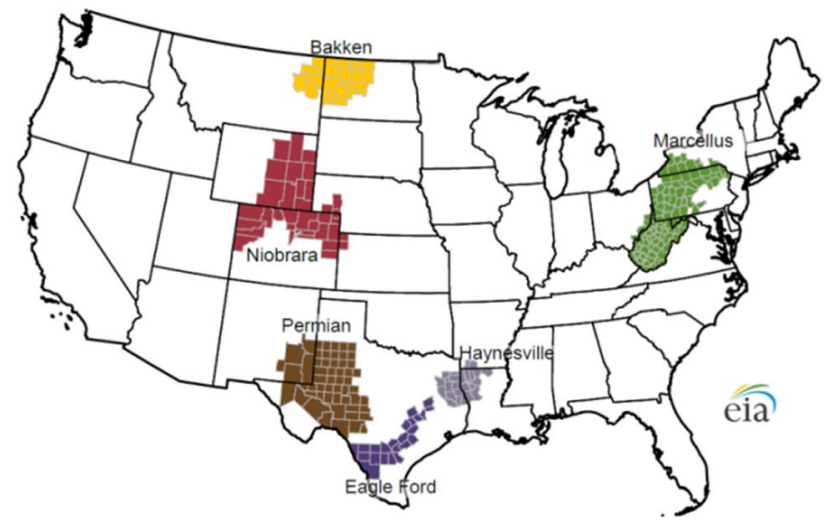

Fig. 1 US Shale hydrocarbon regions (EIA 2021; Yu and Sepehrnoori 2014b)

in a shale matrix, there are four types of pores media i.e. inorganic matrix, organic matrix, hydraulic fractures, and naturally existing fractures (Wang and Reed 2009). In addition, it has ultra-low permeability and low porosity with different other mechanisms such as gas adsorption, gas absorption, gas slippage, and non-Darcy flow, etc. All these parameters significantly affect the gas production and underground reserves evaluation in a variety of ways (Eshkalak et al. 2013, 2014; Lin et al. 2020; Lin and Zhao 2021; Syed et al. 2020a, b, 2021b; Wang et al. 2019; Zhang et al. 2019; Memon et al. 2020, 2021).

Due to the complex matrix structure with low permeabilities and porosities, the shale gas is trapped inside the nano-pores and hence the flow is highly restricted. To produce gas from such a complex system, an interconnected fracture system with extended wells is required (Ayers et al. 2012; Sprunger et al. 2021; Syed et al. 2021a; Zhang et al. 2020). Horizontal drilling, enhanced oil recovery, and hydraulic fracturing are some of the technologies implemented to recover unconventional hydrocarbon reservoirs (Muther et al. 2021, 2022; Syed et al. 2011, 2021a; Yue et al. 2020). Specifically, the horizontal well coupled with multistaged hydraulic fractures has been used quite extensively in enhancing the permeabilities of ultra-tight Marcellus shale matrix (Yu and Sepehrnoori 2014b). Without the horizontal wells and hydraulic fractures, the production of shale gas is economically not justifiable because of not achieving economically feasible production (Bajus 2014; Mengal and Wattenbarger 2011; Muther et al. 2020a, b; Syed et al. 2022).

As shale resources have such a complex system, therefore, the success of any shale gas project relies heavily on defining the appropriate physics. As mentioned earlier, various mechanisms control the gas flow in the shale matrix. However, out of those mechanisms, the study of gas adsorption is very critical because of its high impact on production forecasting and reserve evaluation. Therefore, the adsorption value must be estimated accurately through the experiments (Eshkalak et al. 2013, 2014). Generally, the adsorption is defined through Langmuir isotherm as a function of gas reservoir pressure. The adsorbed gas in terms of Langmuir correlation can be written as:

$G_{s}=\frac{V_{\mathrm{L}} P}{P+P_{\mathrm{L}}}$

here $G_{s}$ represents the gas content (scf/ton), $V_{\mathrm{L}}$ and $P_{\mathrm{L}}$ represent Langmuir volume (scf/ton) and Langmuir pressure (psi) respectively, while $P$ represents the reservoir pressure (psi). The Langmuir volume is defined as the total or maximum gas adsorbed volume by the shale matrix at infinite pressure. In addition, the Langmuir pressure (also termed as critical desorption pressure) is the pressure measured at which half of the $V_{\mathrm{L}}$ can be adsorbed. Generally, higher $P_{\mathrm{L}}$ releases more adsorbed gas and higher $V_{\mathrm{L}}$ represents high adsorbed gas. Also, the gas is desorbed from the shale matrix with decreasing reservoir pressure (Tiab and Donaldson 2016; Yu and Sepehrnoori 2013, 2014a).

Different literature studies analyzed the gas adsorption impact on shale gas recovery. For instance, Cipolla et al. (2009) studied the adsorption contribution in Marcellus and Barnett shale gas recovery for 30 years and concluded an increase of $5-15 \%$ of recovery due to adsorption. In addition, they also concluded that the desorption contributes at later periods of production depending on fracture spacing, reservoir permeability, and flowing bottom hole pressure. Similarly, Thompson et al. (2011) reported an increase in 17\% ultimate gas recovery over 30 years due to gas desorption in the Marcellus shale with a well consisting of 12 stages of hydraulic fractures. In another work, Yu and Sepehrnoori (2014a) evaluated five US shale producers i.e. Barnett, Eagle Ford, New Albany, Marcellus, and Haynesville, and concluded an increase of over 20\% EUR in Marcellus shale due to the gas desorption. The producer well in the study had 70 clusters of fractures. Moreover, Yu and Sepehrnoori (2014b), studied another Marcellus shale region having a well with 18 stages of hydraulic fractures and observed an increase in cumulative gas production (around 10\%) due to the gas desorption. Likewise, Seales et al. (2016) observed an increase in shale gas production in the range of $1.5-5.5 \%$ in Marcellus shale over 20 years due to gas desorption. Nevertheless, most of the aforementioned work studied the gas adsorption-desorption contribution on a single Marcellus shale rock isotherm value with no discussion on other Marcellus shale regions. Additionally, the considered well in those works include multi-clustered fractures with horizontal well. Therefore, a comprehensive analysis of different Marcellus shale regions along with other different well configurations is also required.

This study focuses on understanding the contribution of different gas adsorption phenomena in Marcellus shale for different fractured well configurations. To achieve this 
objective, a mechanistic Marcellus shale model is numerically generated with the available literature data. In addition, various adsorption characteristics (obtained through different experiments conducted in literature) of Marcellus shale are collected and the comparison of Marcellus shale production based on those adsorption characteristics is performed. Additionally, two different well configurations including the fractured vertical well and multi-fractured horizontal well are considered to study the impact of gas desorption on production performance.

\section{Methodology}

The objective of this work is to analyze the impact of adsorption on the Marcellus shale reservoir with different well configurations. A mechanistic model of the Marcellus shale reservoir is numerically generated for the aforementioned objective. The methodology of the presented work (refer to Fig. 2) is summarized into following portions:

\section{a. Model Generation}

i. Specifying the reservoir features including the rock properties and geometry

ii. Specifying the SCAL and PVT information

iii. Specifying different adsorption characteristics

iv. Defining the well features including hydraulic fractures b. Model Prediction

i. Estimation and comparison of shale gas production performance with different adsorption characteristics

ii. Assessment of production responses of fractured horizontal and vertical well

\section{Reservoir features}

An area of around 8.6 acres with $130 \mathrm{ft}$ of reservoir height, $1500 \mathrm{ft}$ width, and $250 \mathrm{ft}$ length of the Marcellus shale portion was numerically generated. The considered well in the base model is horizontal with four fracture clusters in a single stage. In addition, the reservoir has two layers with different porosities i.e. the upper layer is $30 \mathrm{ft}$ with $7.1 \%$ of porosity, while, the lower layer is $100 \mathrm{ft}$ with $14.1 \%$ porosity. Additionally, a few null blocks are taken in the reservoir grid for accurate reserve determination. The null blocks were considered based on the pressure transient reaching the boundaries. Furthermore, several other reservoir characteristics are presented in Table 1. Moreover, the mechanistic model is shown in Fig. 3.

It is recognized that the depletion of reservoir pressure results in a significant increase in net stresses. This mechanism causes a reduction in reservoir rock permeability and porosity. Such effect is modeled in this mechanistic model through permeability and porosity multipliers with changing pore pressure. The permeability multiplier for this study

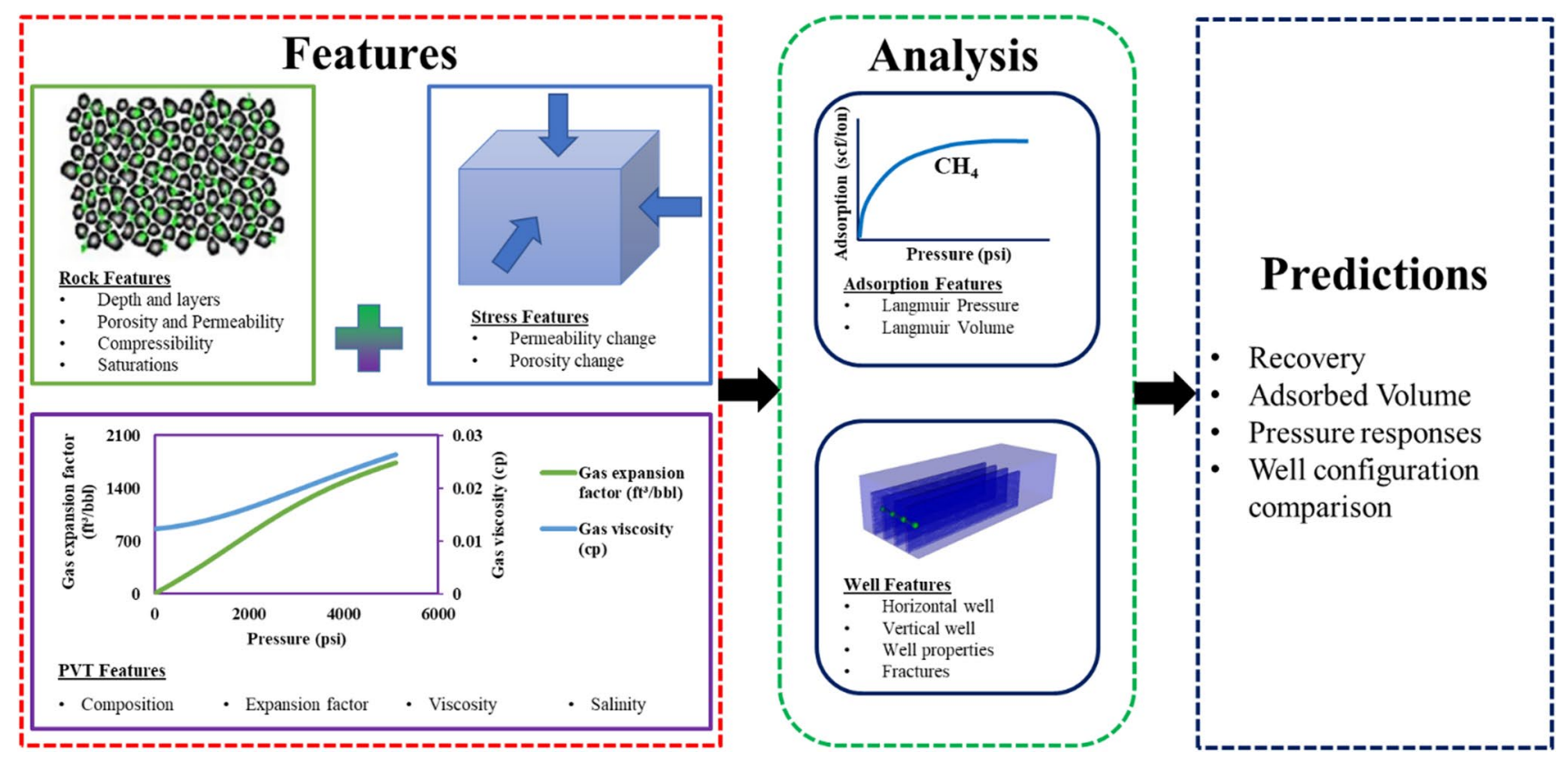

Fig. 2 Methodology workflow 
Table 1 Reservoir Characteristics (El Sgher et al. 2018; Jia et al. 2017; Yu et al. 2016)

\begin{tabular}{ll}
\hline Properties & Values \\
\hline Reservoir porosity & $7.1-14.1 \%$ \\
Reservoir permeability & $65 \mathrm{nD}$ \\
Initial water saturation & $10 \%$ \\
Total compressibility & $3 \times 10^{-6}$ \\
Reservoir pressure & $5100 \mathrm{psi}$ \\
\hline
\end{tabular}

is collected from a recent study (El Sgher et al. 2018). The behavior of the defined permeabilities under stress versus the pore pressure is shown in Fig. 4. In addition, the porosities are determined through the permeabilities values through Kozeny-Carman (KC) model (Lala 2018). The KC model can be written as: $k=10^{9} \frac{d^{2}}{72 \tau^{2}} \frac{\varphi^{3}}{(1-\varphi)^{2}}$

where $d$ represents average grain size (diameter) in $\mathrm{mm}, k$ represents permeability (md), $\varphi$ represents porosity.

The determined porosities are then normalized to be input in the mechanistic model. The calculated porosities with their multipliers versus pore pressures are plotted in Fig. 5.

\section{PVT and rock-fluid features}

In this study, the PVT properties are determined through the gas-specific gravity value. The gas-specific gravity is considered to be around 0.58 with $130{ }^{\circ} \mathrm{F}$ of reservoir temperature (Yu et al. 2016). In addition, the gas-water PVT model is considered to develop fluid properties under various pressure conditions. The calculated values of gas viscosity $\left(\mu_{\mathrm{g}}\right)$
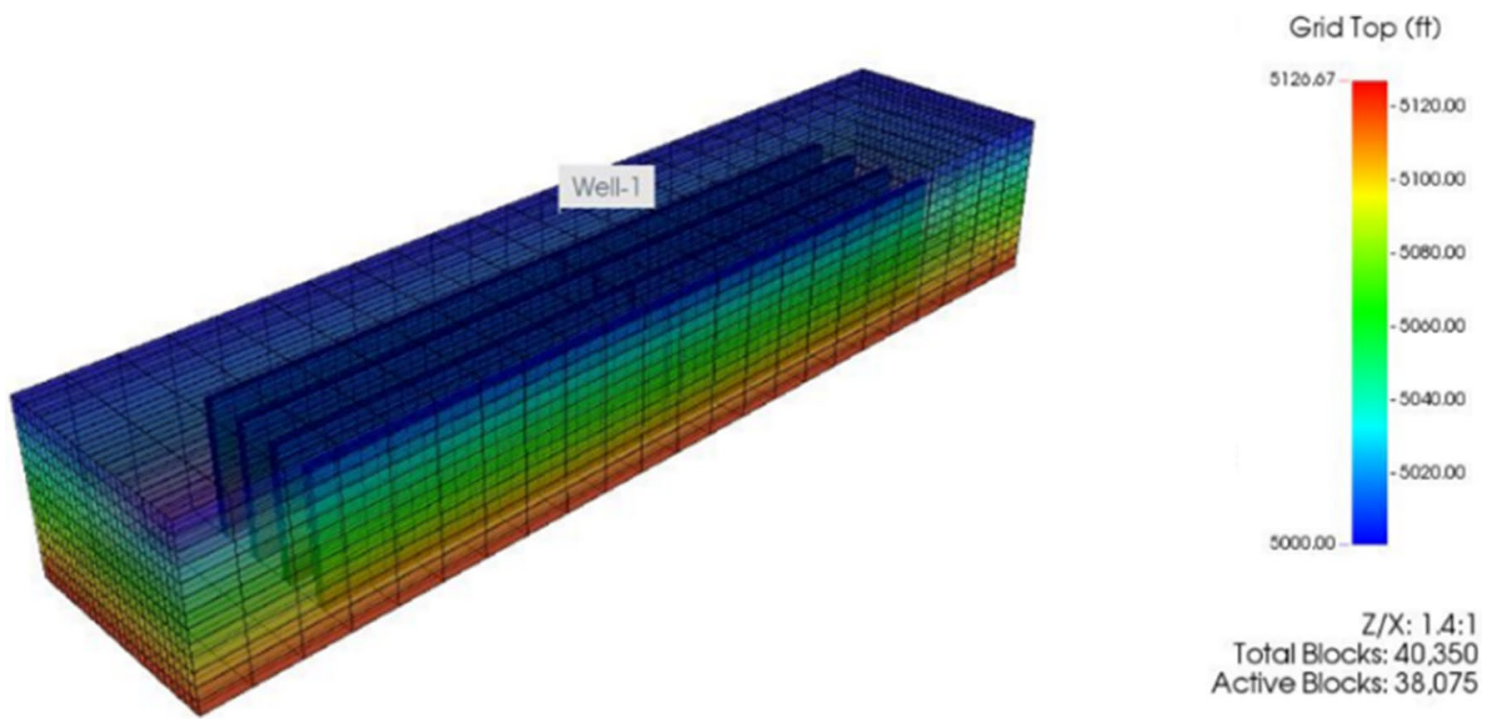

Fig. 3 Mechanistic model of Marcellus Shale with single-stage 4-clusters fracture
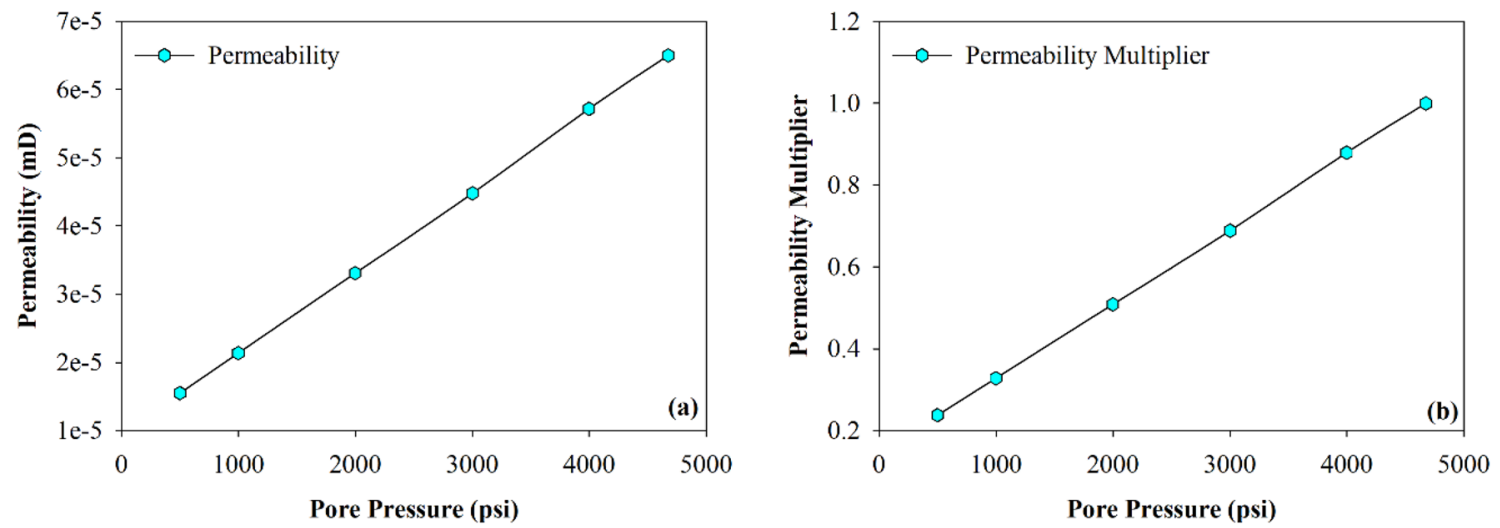

Fig. 4 Pore pressure effect on a permeability, b permeability multiplier 

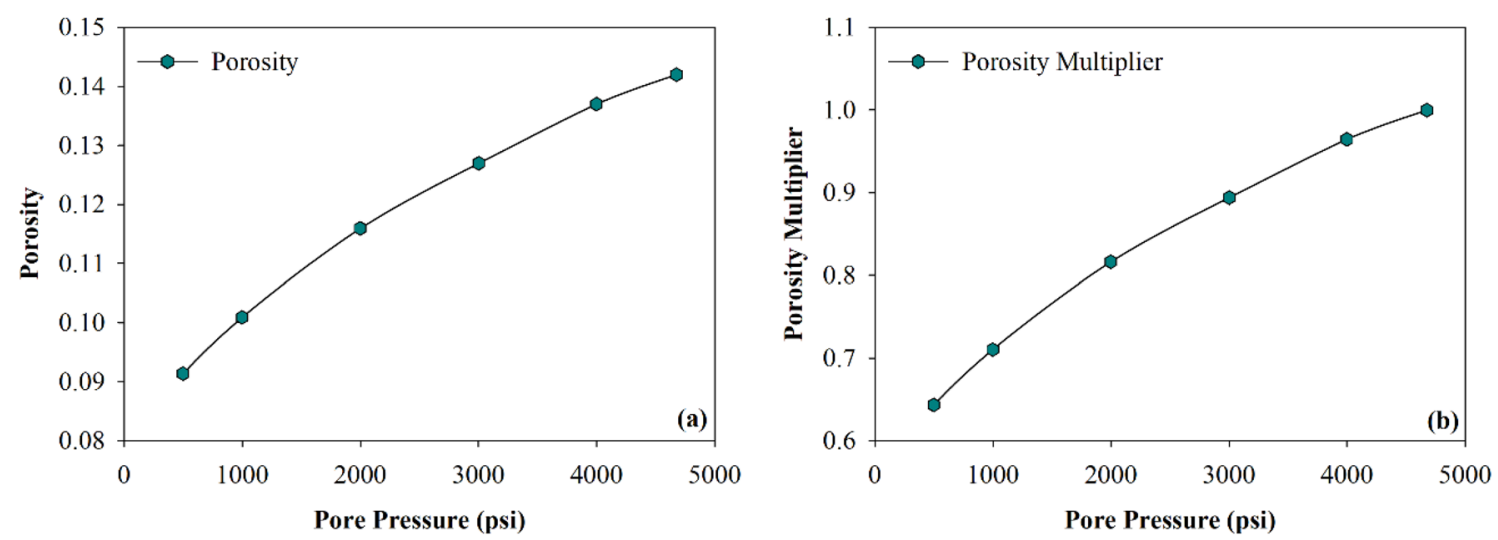

Fig. 5 Pore pressure effect on a porosity, b porosity multiplier

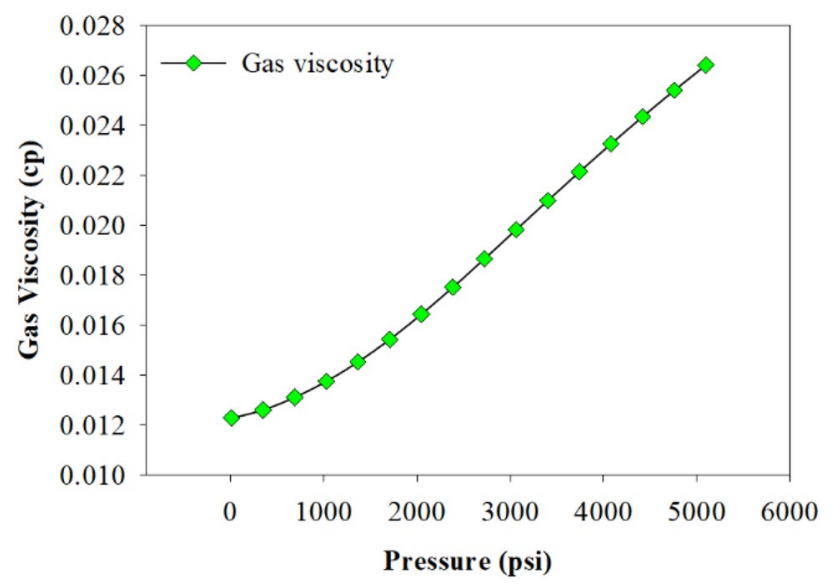

Fig. 6 Gas viscosity response with changing pressure

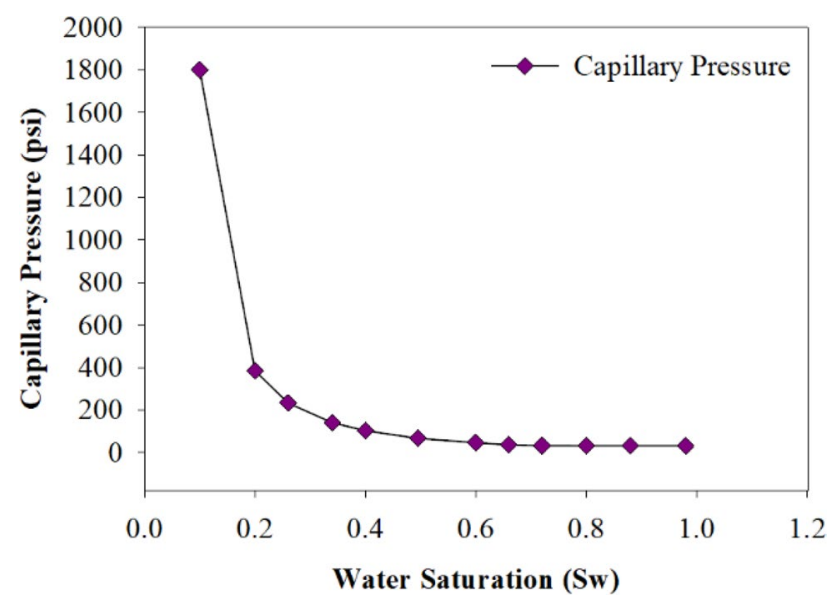

Fig. 8 Capillary pressure curve-Marcellus Shale

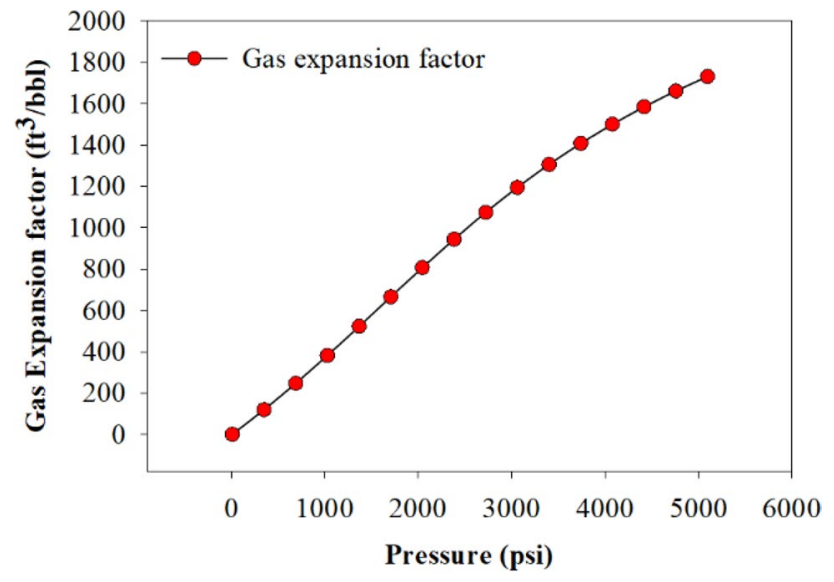

Fig. 7 Gas expansion factor response with changing pressure

and gas expansion factor $\left(E_{\mathrm{g}}\right)$ are plotted in Figs. 6 and 7 respectively. In addition, the rock-fluid properties i.e. capillary pressure and gas-water relative permeability curve are

taken from the literature (Seales et al. 2016) and are plotted in Figs. 8 and 9 respectively. In this Marcellus shale model, the low initial water saturation is assumed and therefore the impact of capillary pressure will be negligible.

\section{Adsorption curves}

To incorporate the adsorption-desorption behavior in the mechanistic model, the Langmuir isotherm curves are used in this study. To investigate the adsorption effect for the samples of different Marcellus shale regions, various laboratorymeasured isotherms are taken from the literature. A summary of adsorption characteristics is presented in Table 2 . Based on these characteristics, the adsorption curves are generated through Eq. 1 and plotted in Fig. 10.

\section{Well features}

The base well model, in this study, consists of a horizontal well which is placed in the lower portion of the mechanistic

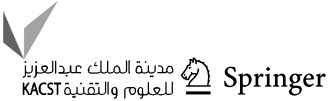




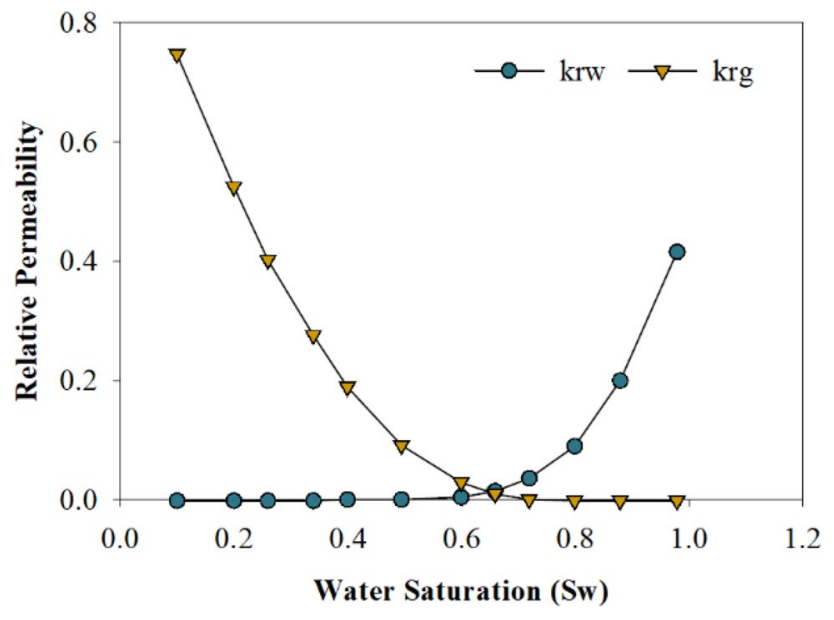

Fig. 9 Relative permeability curves-Marcellus Shale

Table 2 Laboratory-based adsorption characteristics gathered through literature

\begin{tabular}{llll}
\hline Case & $\begin{array}{l}V_{\mathrm{L}} \\
\text { Scf/ton }\end{array}$ & $\begin{array}{l}P_{\mathrm{L}} \\
\text { psi }\end{array}$ & Reference \\
\hline 1 & 28.3 & 741.5 & Jia et al. (2017) \\
2 & 54 & 240 & El Sgher et al. (2021) \\
3 & 115 & 673 & Seales et al. (2016) \\
4 & 196.4 & 535 & Yu et al. (2016) \\
5 & 160.3 & 1240 & \\
6 & 100.6 & 1144 & \\
\hline
\end{tabular}

model. The well includes 4 evenly spaced fracture clusters in a single fracturing stage (refer to Fig. 11). In addition, due to the transient flow near the wellbore and the fractures, the local grid refinement (LGR) with logarithmic cell spacings is utilized. Also, non-Darcy flow is specified in the fractures based on the Forchheimer number and its weighting factor. A summary of different well features is provided in Table 3.

For fractured-vertical well cases, similar fracture properties are considered. In addition, a total of five fractures, each with $20 \mathrm{ft}$ height (a cumulative height of $100 \mathrm{ft}$ ) is developed to replicate the $100 \mathrm{ft}$ height in the lower region of the mechanistic model (refer to Fig. 12).

\section{Cases description}

After specifying the mechanistic reservoir model properties, a detailed analysis for understanding the adsorption behavior of samples taken from different Marcellus shale regions has been conducted. The analysis has been performed on the following responses in order to develop a detailed insight into the adsorption mechanism:

i. Analysis on pressure change

ii. Analysis on gas saturation variation

iii. Comparison of adsorbed gas volumes

iv. Assessment of gas rates

v. Assessment of cumulative gas production

vi. Assessment of gas recovery factor

In addition, the fractured vertical well response is also analyzed so that the desorption contribution to such well configuration can be understood.

\section{Results and discussion}

In order to analyze the influence of adsorption-desorption, the reservoir was produced at the sand face pressure limit of $1000 \mathrm{psi}$ for 30 years. In addition, the gas rate is constrained at $10 \mathrm{MMSCF} / \mathrm{D}$. The behavior of the reservoir is analyzed on the basis of pressure change response, gas production
Fig. 10 Langmuir isotherms based on adsorption characteristics

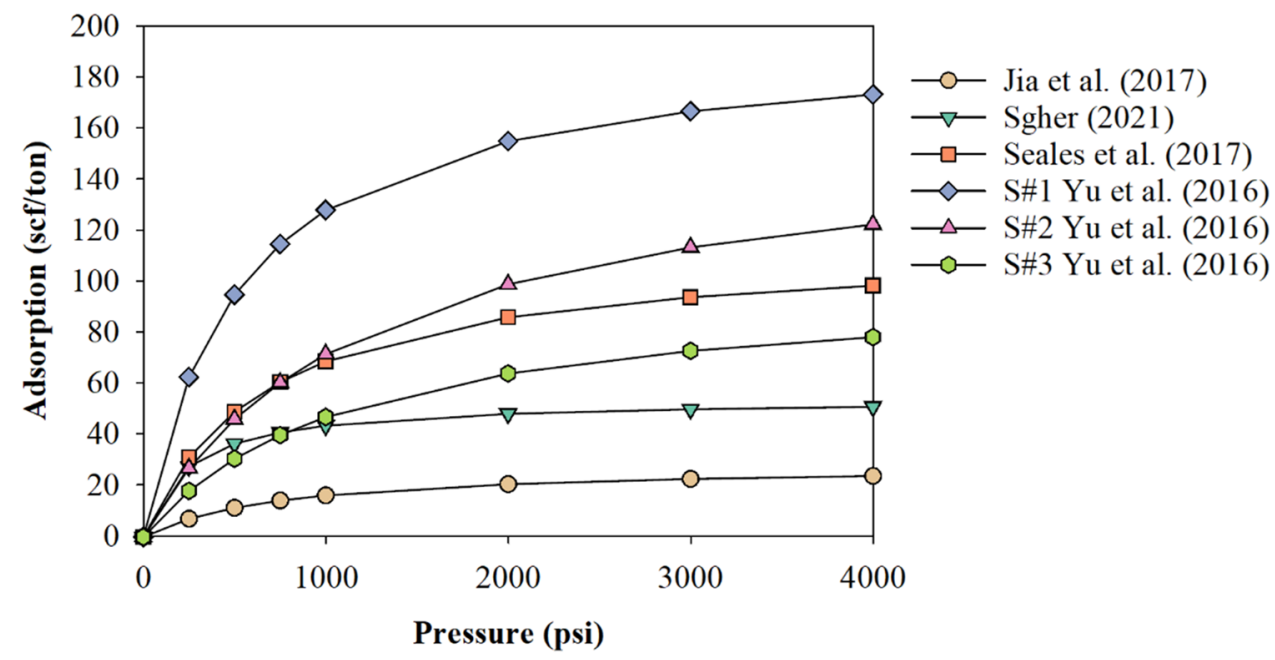




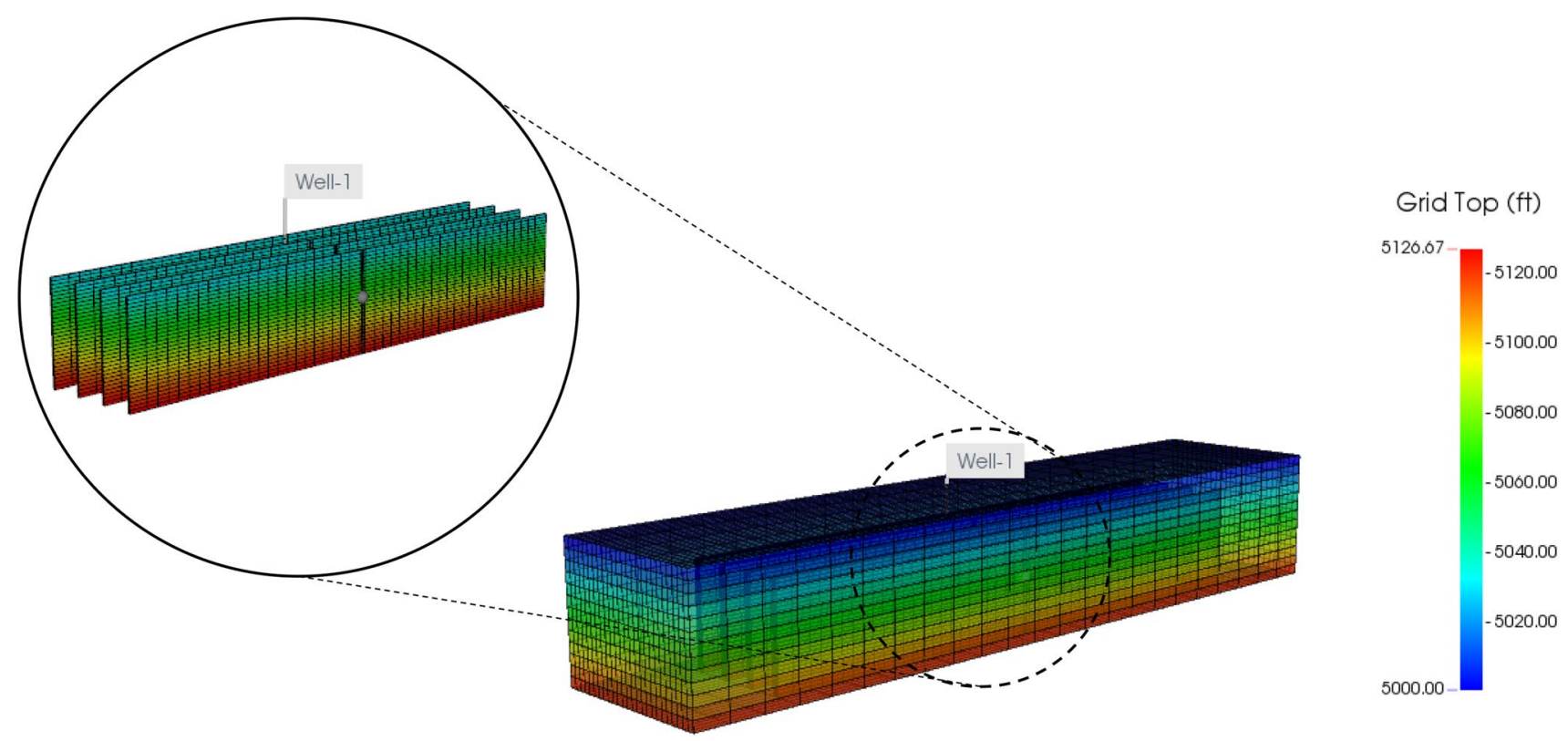

Fig. 11 Generated planer four-clusters single staged fracture

Table 3 Well and fracture properties (Yu et al. 2016)

\begin{tabular}{ll}
\hline Properties & Values \\
\hline Fracture half-length & $400 \mathrm{ft}$ \\
Fracture conductivity & $3.5 \mathrm{md} . \mathrm{ft}$ \\
Fracture width & 0.1 inches \\
Fracture height & $100 \mathrm{ft}$ \\
Number of clusters & 4 \\
Cluster spacing & $50 \mathrm{ft}$ \\
BHP limit & $1000 \mathrm{psi}$ \\
\hline
\end{tabular}

response including the gas recovery, gas rates, and cumulative production, and adsorbed volume change over time. Furthermore, a comparison of adsorption cases with no adsorption case has been made. It should be noted that the results presented from "Analysis of pressure change" through "Assessment of gas recovery factor" sections include a horizontal well containing 4-clusters single-stage fracture.

\section{Analysis of pressure change}

The depletion of reservoir pressure of all the cases over time is presented in Fig. 13. The figure shows that the pressure depletions are approximately similar in all cases representing the effect of ultra-low permeability in the Marcellus shale reservoir. Additionally, the behavior of pressure change over the spatial region for 1,5 , and 30 years is shown in Fig. 14. As seen in Fig. 14i, the pressure transient has concentrated around the fractures and not reached the boundaries of the reservoir indicating that the reservoir is in the transient flow regime. As the reservoir is produced for 5 years, the flow regime is changed to apparent boundary dominated flow (transitional flow regime) with the top and bottom reservoir boundaries reached by the pressure transient (refer to Fig. 14ii). At the end of 30 years, all the defined reservoir boundaries are contacted by the pressure transient (refer to Fig. 14iii). This concludes that the pressure transient reaches the reservoir boundaries after long flow periods in Marcellus shale, however, producing such reservoir for such a long period is neither economically nor physically justifiable. It should be noted that few of the reservoir grid blocks are changed to null blocks to estimate the reserves accurately. Otherwise, the left and right reservoir boundaries are geologically bigger.

\section{Analysis on gas saturation variation}

In addition to the pressure response, the gas saturation variation for all the cases within the time domain of 1,5 , and 30 years is shown in Fig. 15. Initially, the gas saturation in the reservoir was about $90 \%$. As seen in Fig. 15, most of the reservoir portion remains unswept with a small gas recovery near the fractured area at the end of 1st year of production. After 5 years of production, the gas saturation is significantly decreased. Similarly, after 30 years, the saturation of gas is decreased further, and this saturation effect is reached to the defined reservoir boundaries. This response is similar to the pressure depletion response of the reservoir, where the reservoir boundaries are reached by the pressure transient.

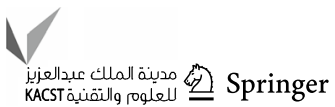




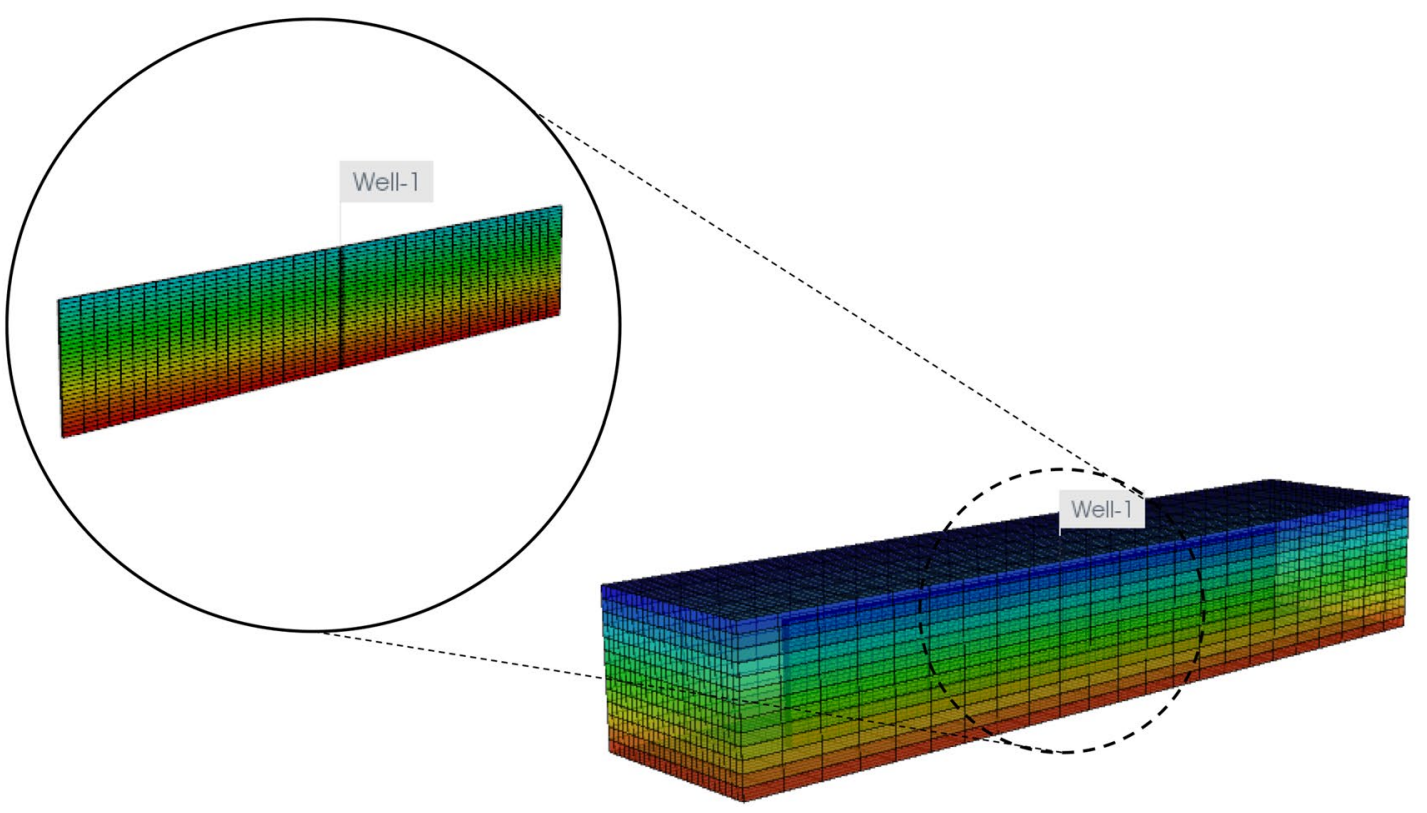

Grid Top (ft)

5120.67

$-5120.00$

$-5100.00$

$-5080.00$

$-5060.00$

$-5040.00$

$-5020.00$

5000.00

Fig. 12 Vertical well with 5-planar fractures each of height $20 \mathrm{ft}$

Fig. 13 Depletion of reservoir pressures over time

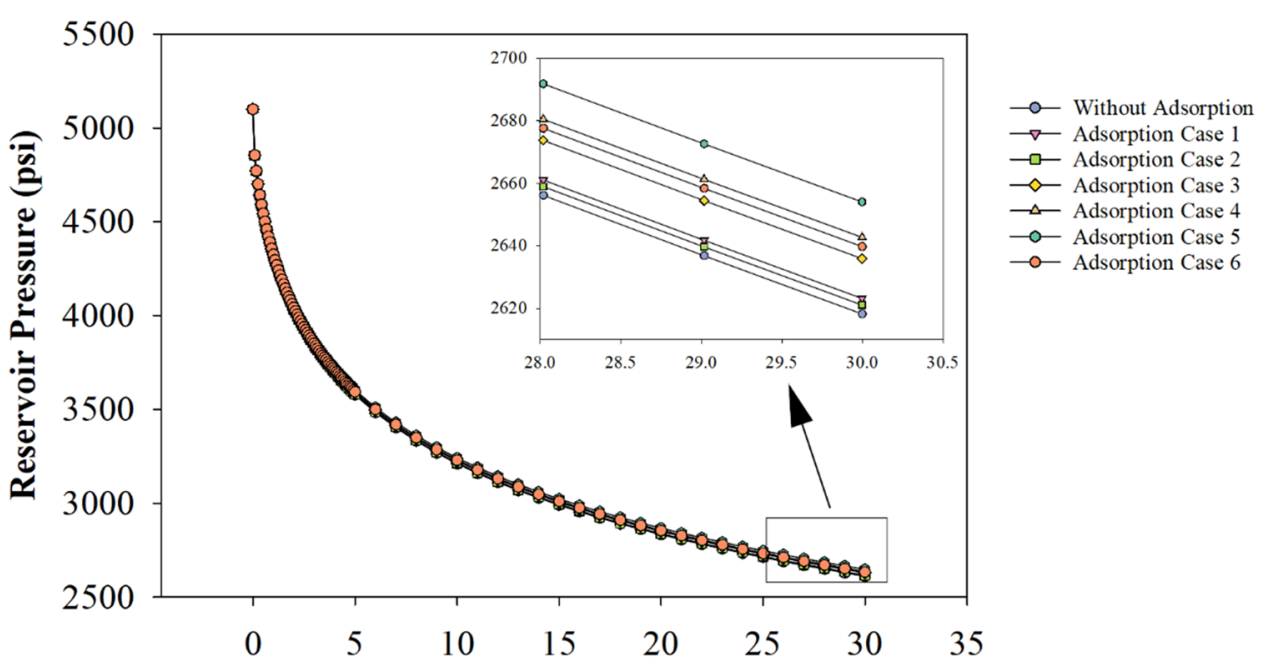

Time (years)

\section{Comparison of adsorbed gas volumes}

After defining the adsorption characteristics into the mechanistic model, it has been evaluated that the reservoir gas volumes are increased significantly due to the adsorption of the gas in the shale matrix. Before adsorption, the gas volume was estimated to be $1.3 \mathrm{BSCF}$ that was increased based on different adsorption characteristics of Marcellus shale regions. The different gas adsorbed volume depending on the defined adsorption characteristics is provided in Table 4.
From the details provided in Table 4, it is observed that Case 4 with relatively high adsorbed gas content $\left(V_{\mathrm{L}}\right)$ has the highest adsorbed gas volume, whereas, Case 1 with low $V_{\mathrm{L}}$ has relatively lower adsorbed gas in the shale matrix. This comparison shows that the $V_{\mathrm{L}}$ is the main controlling factor of adsorbed gas volume in the shale system. Now, since all the cases contain significant volumes of adsorbed gas, therefore, the pressure depletion over time will contribute a significant amount to the production of gas. This behavior is presented in Fig. 16, which indicates that the adsorbed volume decreases over time resulting in the desorption and production of gas. 
Fig. 14 Depletion of reservoir pressure after (i) 1 year (ii) 5 years (iii) 30 years

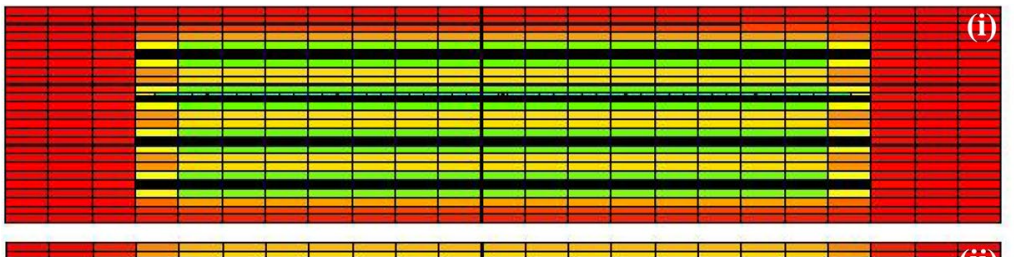

Pressure (psi)

5100.24

$-5000.00$

$-4500.00$

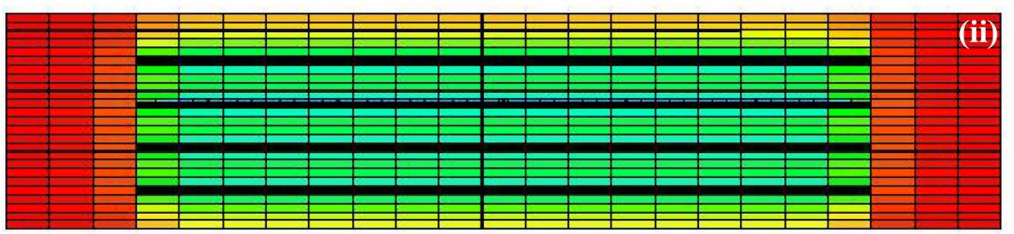

$-4000.00$

$-3500.00$

$-3000.00$

$-2500.00$

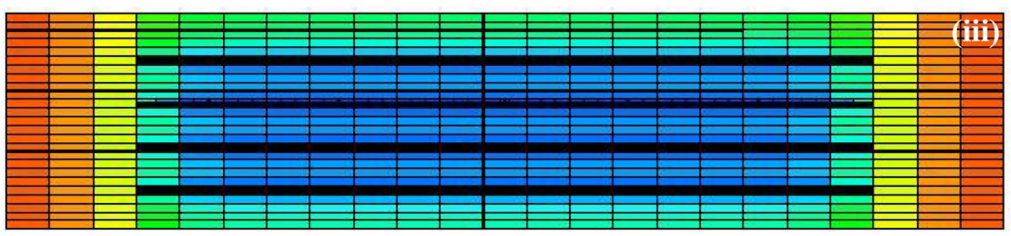

$-2000.00$

$-1500.00$

999.50

1000.00

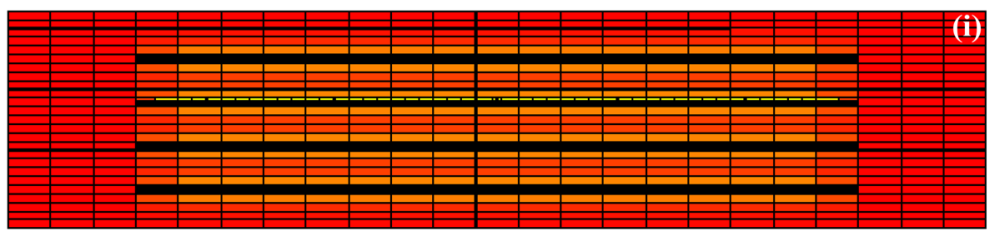

Gas Saturation

Fig. 15 Variation of gas saturation after (i) 1 year (ii) 5 years (iii) 30 years

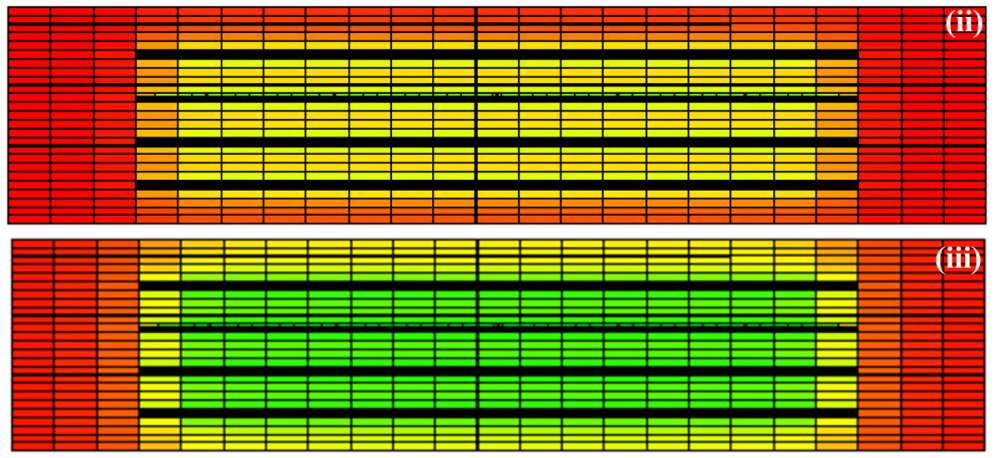

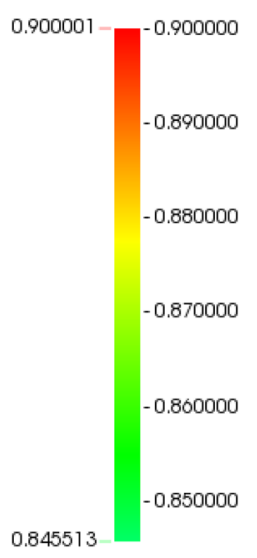

0.845513
Table 4 Summary of adsorbed gas volumes for different Marcellus shale adsorption characteristics

\begin{tabular}{lllll}
\hline Case & $\begin{array}{l}V_{\mathrm{L}} \\
\text { Scf/ton }\end{array}$ & $\begin{array}{l}P_{\mathrm{L}} \\
\mathrm{psi}\end{array}$ & $\begin{array}{l}\text { Adsorbed gas volume } \\
\mathrm{ft}^{3}\end{array}$ & $\begin{array}{l}\text { Initial gas volume } \\
\mathrm{ft}^{3}\end{array}$ \\
\hline 1 & 28.3 & 741.5 & $4.82 \mathrm{E}+07$ & $1.30 \mathrm{E}+09$ \\
2 & 54 & 240 & $1.01 \mathrm{E}+08$ & \\
3 & 115 & 673 & $1.99 \mathrm{E}+08$ & \\
4 & 196.4 & 535 & $3.49 \mathrm{E}+08$ & \\
5 & 160.3 & 1240 & $2.52 \mathrm{E}+08$ & \\
6 & 100.6 & 1144 & $1.62 \mathrm{E}+08$ & \\
\hline
\end{tabular}

\section{Assessment of gas rates}

The simulated gas rates comparison of all the cases including the no-adsorption and adsorption are presented in Fig. 17 (linear scale) and Fig. 18 (semi-log scale). Similar to the pressure change behavior in the earlier section, the gas rates are also found to be relatively closer to each other. From the zoomed portion in the plots, however, it can be seen that the gas rates of Case 4, Case 5, and Case 6 are slightly higher than the other cases. In general, it can be identified from the gas rate plots that the rates are significantly dropped during the initial production periods from around $10 \mathrm{MMSCF} / \mathrm{D}$ to $0.3 \mathrm{MMSCF} / \mathrm{D}$ indicating the reservoir is flowing under a transient flow regime. The flow regime is then changed to a pseudo-state regime after one year of production due to the communication of pressure transient with the reservoir boundaries. After reservoir production of over 30 years, the well has been producing in the range of $0.0135-0.015$ MMSCF/D. It should be noted that even with moderate numbers of fractures with high fracture half-lengths, the behavior will still be similar i.e. the rates will decline abruptly during 
Fig. 16 Comparison of adsorbed gas volumes depletion over time
Fig. 17 Comparison of gas rates of specified adsorption cases (linear scale)

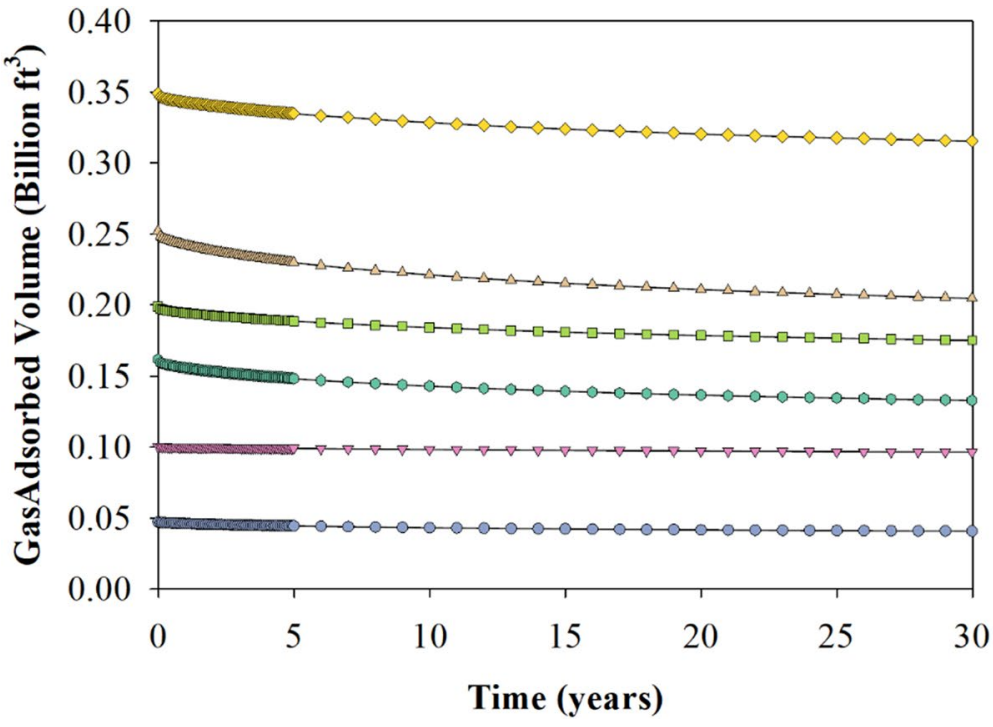

- - Adsorption Case 1 $\rightarrow$ Adsorption Case 2 $\rightarrow-$ Adsorption Case 3 $\neg$ Adsorption Case 4 $\rightarrow$ Adsorption Case 5 - - Adsorption Case 6

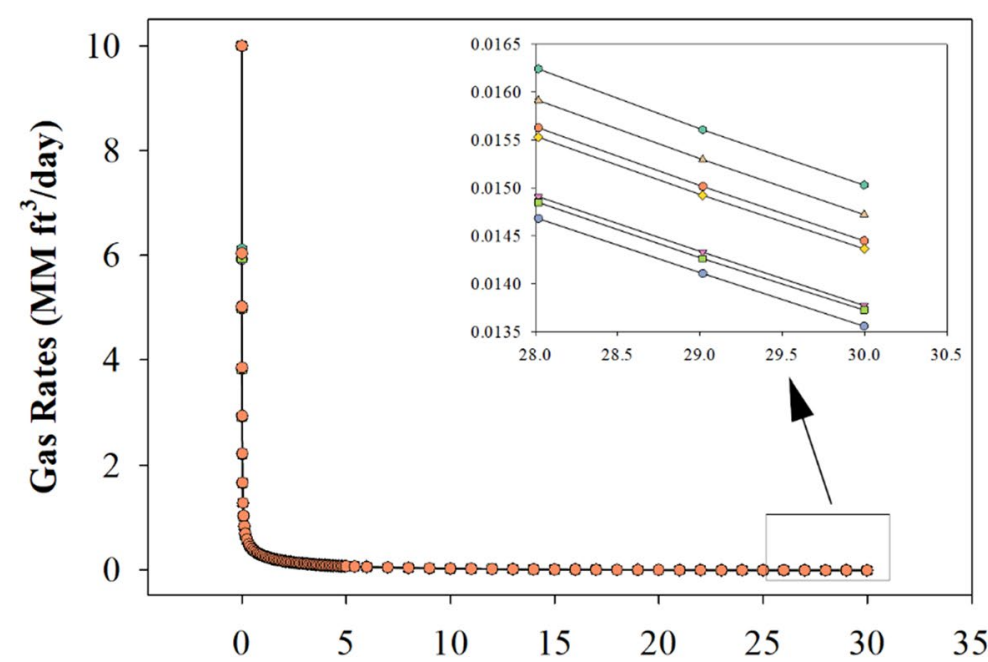

Time (years)

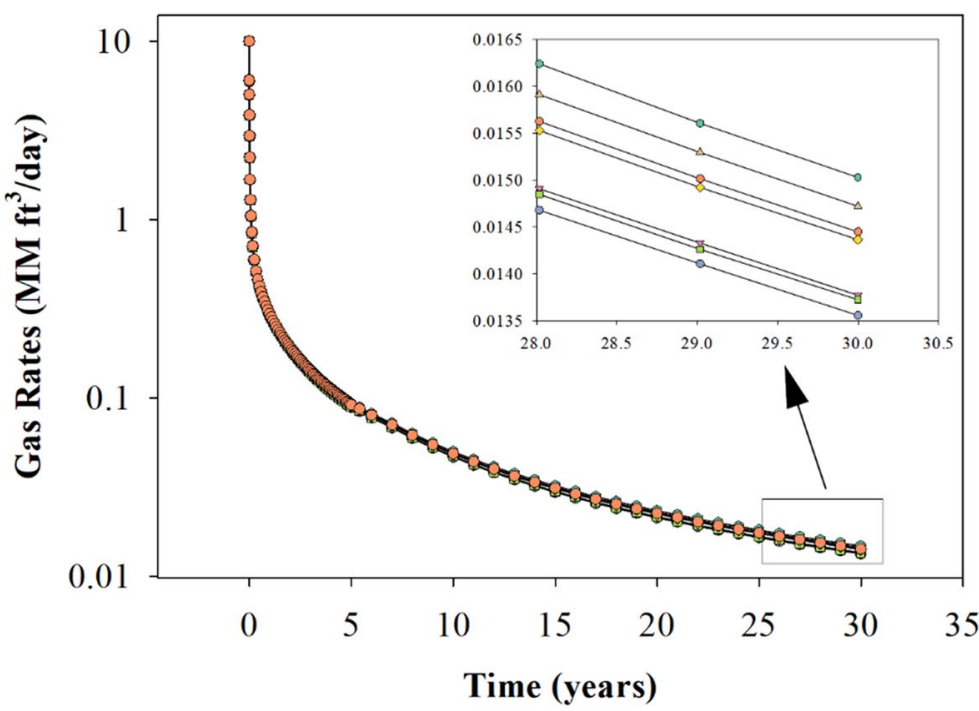

$\multimap$ Without Adsorption $\longrightarrow$ Adsorption Case 1 $\rightarrow$ Adsorption Case 2 $\multimap$ Adsorption Case 3 $\longrightarrow$ Adsorption Case 4 - - Adsorption Case 5 $\multimap$ Adsorption Case 6
Fig. 18 Comparison of gas rates of specified adsorption cases (semi-log scale) 
the initial years and flow at lower rates later. This behavior is due to the intricate characteristics including the complex physics and nano-pores of the Marcellus shale.

\section{Assessment of gas cumulative production}

After defining all the complex physics in the mechanistic model of Marcellus shale, the simulation has been carried out to assess the gas cumulative production for 30 years of all the specified cases (refer to Fig. 19). It can be analyzed from the cumulative production curves that the gas adsorption contribution is insignificant i.e. in the range of around $0.2-3 \%$ production increase in comparison with the no-adsorption case for the first 5 years. For higher production periods i.e. upto 30 years, the increase in production observed is around $0.4-5 \%$ (refer to Fig. 20).

It should be noted that because of the different adsorption characteristics, including the different combinations of volume and pressure, of the samples taken from various Marcellus shale regions, the comprehensive discussion over their comparison and contribution to the production is difficult. In general, although, a conclusion can be established that the gas desorption from the Marcellus shale can contribute around $0.4-5 \%$ production increase over 30 years with the specified hydraulically fractured horizontal well configuration.

\section{Assessment of gas recovery factor}

With the cumulative gas production, the gas recovery factor response is also simulated and presented in Fig. 21. The plot shows that the gas recovery factor of the no-adsorption case is higher than all the adsorption cases. The reason for such a response is that the total gas volume in the shale system gets

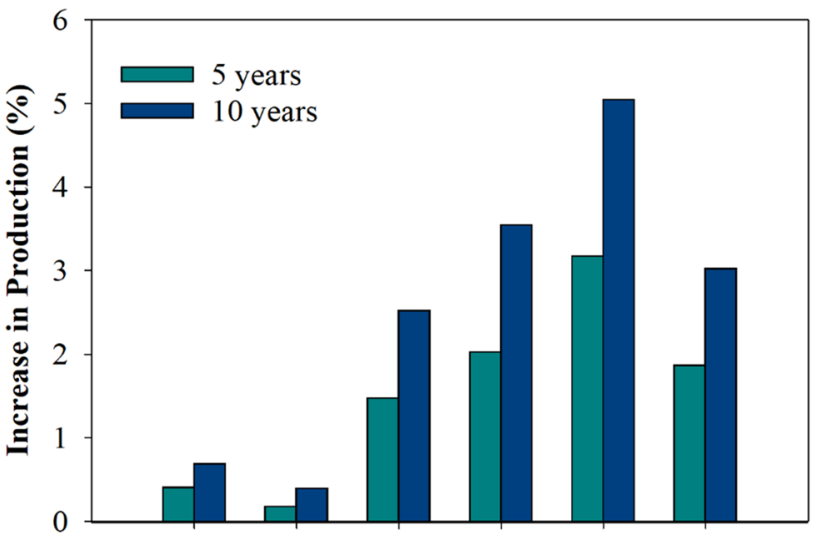

Case 1 Case 2 Case 3 Case 4 Case 5 Case 6

Fig. 20 Cumulative gas production increase (in \%) from the withoutadsorption case

increased because of the adsorption. Hence, even though the gas production is higher in all the adsorption cases, the recovery factor is lower because of the high total gas in place in the shale system due to the gas adsorption.

\section{Analysis on fractured vertical well configuration}

Apart from horizontal well configuration, the vertical well with fractures response on gas desorption is also investigated. The simulated results of the production performances i.e. gas production rates, cumulative production, and recovery factors at specified adsorption scenarios are presented in Figs. 22, 23, and 24 respectively. It can be observed from Fig. 23 that the gas desorption from the shale is minimal resulting in low production increments in 30 years i.e. only $2.7 \%$ in Case 5 , which is the maximum
Fig. 19 Comparison of cumulative gas production of specified adsorption characteristics of the Marcellus shale
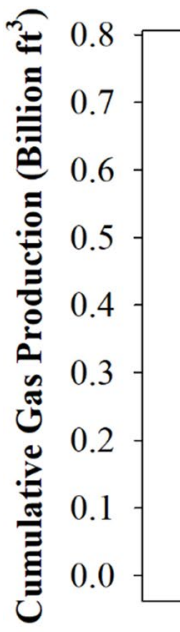

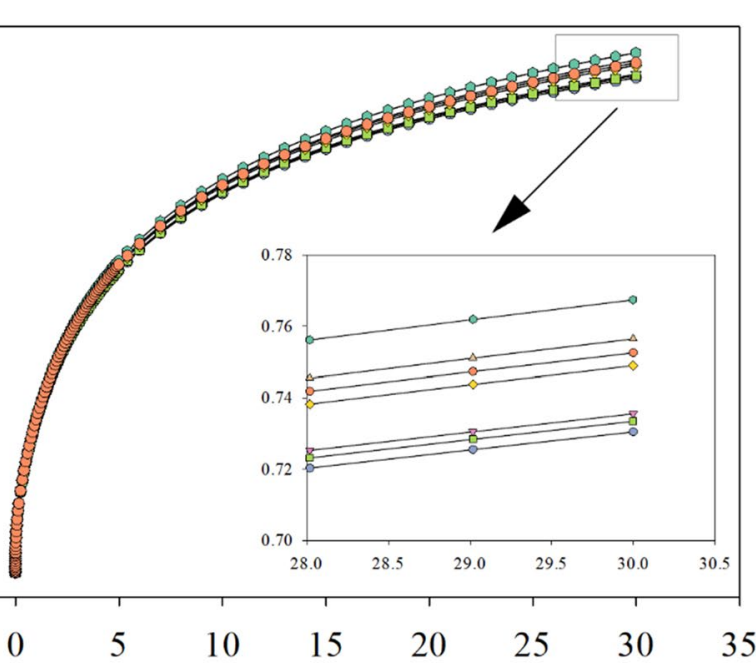

Time (years)
- Without Adsorption $\rightarrow$ Adsorption Case 1 $\rightarrow-$ Adsorption Case 2 $\neg-$ Adsorption Case 3 $\neg$ Adsorption Case 4 $\multimap$ Adsorption Case 5 $\multimap$ Adsorption Case 6 
Fig. 21 Comparison of gas recovery factor of specified adsorption characteristics of the Marcellus shale
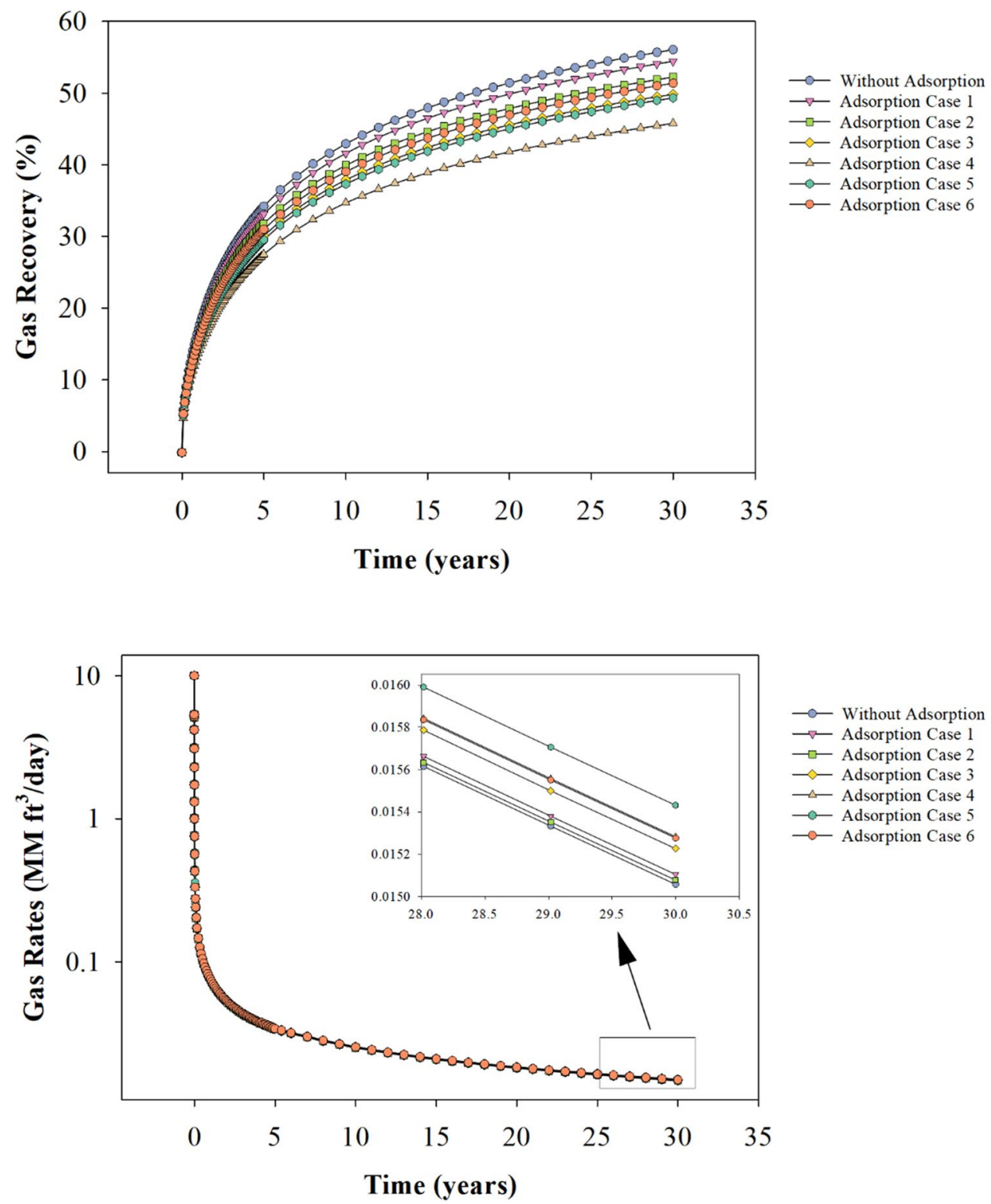

Fig. 22 Comparison of gas rates of specified adsorption cases for the fractured vertical well out of other cases. Case 5 has cumulative production of approximately $0.321 \mathrm{BSCF}$ in comparison to the cumulative production of $0.312 \mathrm{BSCF}$ for the case having no adsorption component. Such observed increment is fairly low, i.e. less than a half, compared to the single-stage hydraulically fractured horizontal well. In addition, the cumulative gas production of a fractured horizontal well, i.e. over $0.76 \mathrm{BSCF}$, is relatively higher than the fractured vertical configuration, i.e. around $0.321 \mathrm{BSCF}$. This represents that around 2.35 times higher gas production is obtained through the multi-fractured horizontal well. On the other hand, the gas recovery physics for the fractured vertical well configuration is similar to the case defined earlier i.e. the recovery factor is lower for the cases with adsorption because the gas adsorption increase the total gas in place.
There are multiple reasons for this low gas production including the lower pressure depletion (refer to Fig. 25), and minimal gas drainage (refer to Fig. 26) from the shale system. To obtain the gas production comparable of fractured horizontal well configuration, a total of 4 vertical wells are required to be drilled and fractured that is economically not feasible. The analysis also shows that gas desorption and gas production is higher in large fracture networks (as in the case of single-stage four clusters fractured horizontal well) compared to smaller networks (multi-fractured vertical well). Hence, the multi-clustered horizontal well configuration is most suited in the Marcellus shale that increases the gas production significantly and is also economically viable. 
Fig. 23 Comparison of cumulative gas production of specified adsorption characteristics for the fractured vertical well
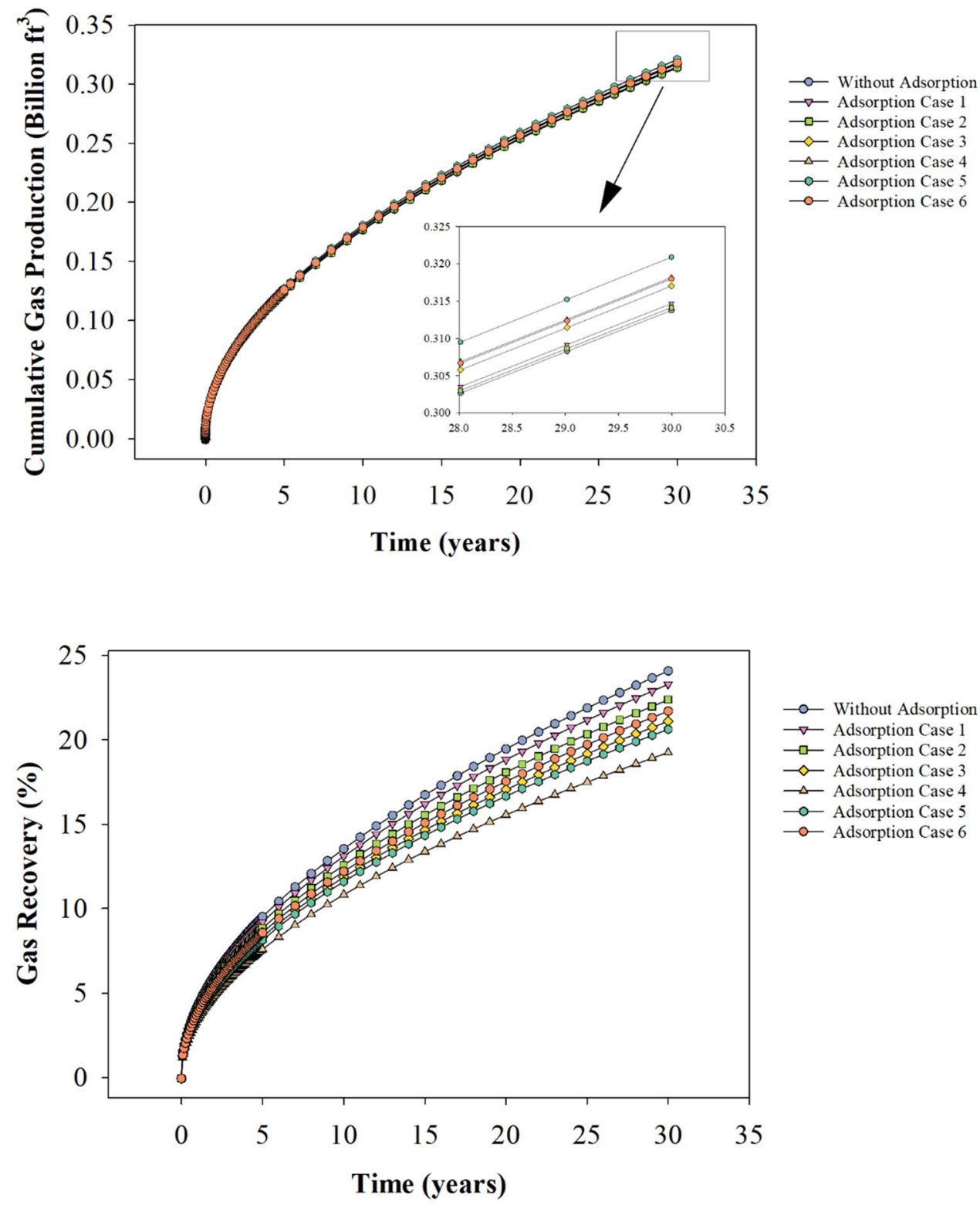

Fig. 24 Comparison of gas recovery factor of specified adsorption characteristics for the fractured vertical well

\section{Conclusions}

This study focuses on understanding the contribution of different gas adsorption characteristics (rock types) in Marcellus shale for different fractured well configurations. To achieve this objective, a mechanistic Marcellus shale model is numerically generated with the available literature data. In addition, various adsorption characteristics (literature-based experimental results) of Marcellus shale are collected for accurately defining the physics of this shale system. Moreover, the Marcellus shale production based on those adsorption characteristics is assessed. Additionally, two different well configurations including the multi-fractured vertical and horizontal well are considered separately to study the impact of gas desorption on the Marcellus shale production performance. From the numerical analysis, the following conclusions have been made:

1. Gas adsorption-desorption highly affects the gas production and reserves evaluation of the Marcellus shale. Ignoring the gas adsorption-desorption effect during numerical simulation causes the underestimation of gas production and shale reserves estimations.

2. The flow regime in the Marcellus shale includes the transient flow during the initial flow periods which then changes to transitional flow for the rest of the reservoir production life. In addition, the pressure transient is not concentrated to fracture only and reaches the specified

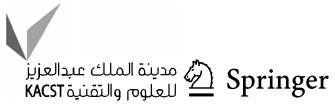


Fig. 25 Depletion of reservoir pressure in fractured vertical well after (i) 1 year (ii) 5 years (iii) 30 years

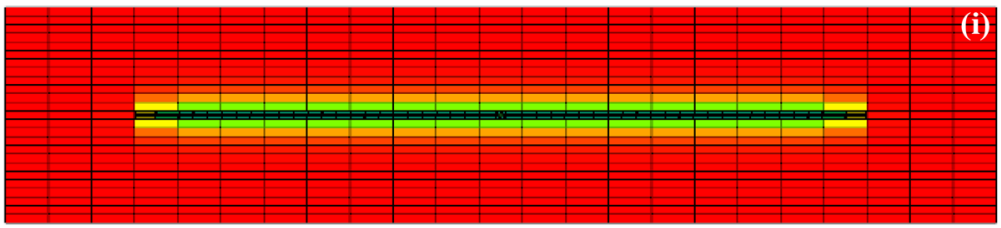

Pressure (psi)

5100.55

$-5000.00$

$-4500.00$

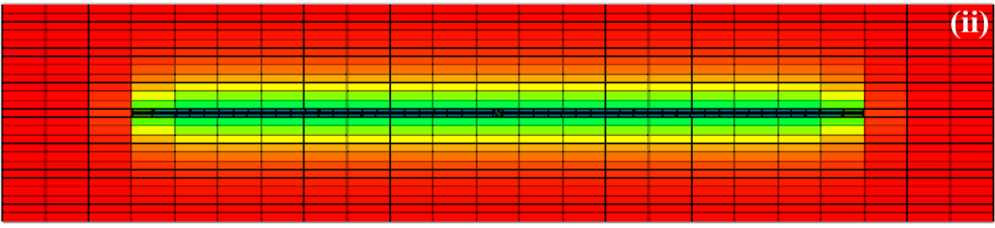

$-4000.00$

$-3500.00$

$-3000.00$

$-2500.00$

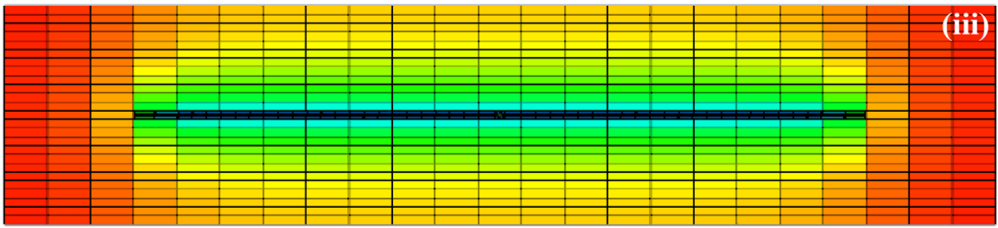

2000.00

$-1500.00$

999.60

1000.00
Fig. 26 Gas saturation variation in fractured vertical well after (i) 1 year (ii) 5 years (iii) 30 years

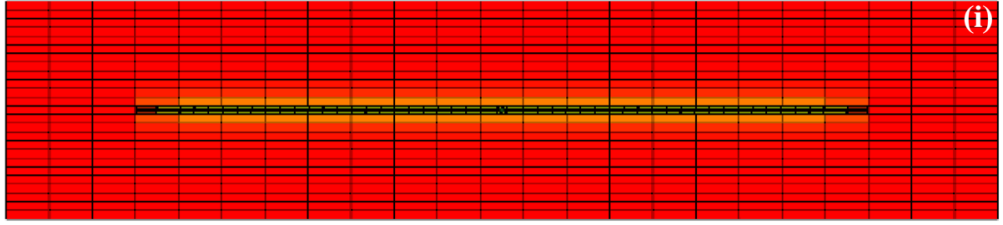

Gas Saturation

0.900003
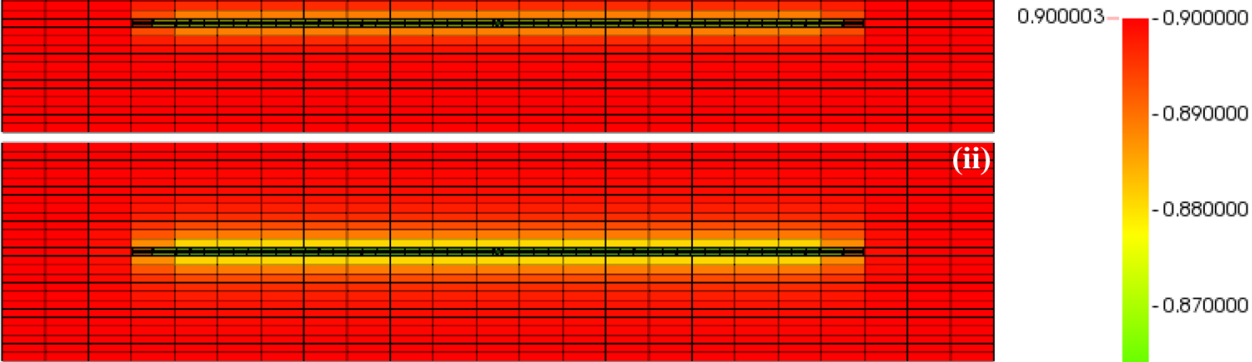

(ii)

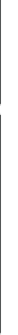

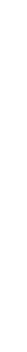

\section{$-0.890000$ \\ $-0.880000$ \\ $-0.870000$ \\ $-0.860000$ \\ $-0.850000$}

0.845321 boundaries opposite to the fracture propagation direction.

3. The desorption impact during the initial production periods is insignificant with $0.2-3 \%$ production increment in 5 years for different gas adsorption characteristics. After 30 years of production through a single-stage fractured horizontal well, a maximum of $5 \%$ production increment is observed because of gas desorption. This concludes that the desorption impact is higher when the reservoir is produced over longer periods which provides sufficient time for the gas to desorb from the complex shale system.

4. Despite the increase in cumulative gas production because of desorption, the gas recovery factor is lower than the no-adsorption case because a significant portion of the gas is still adsorbed onto the shale matrix contributing to overall reserves. In general, with the increase of adsorbed gas reserves due to high Langmuir volume, the recovery factor decreases.

5. The gas production responses are different based on the different gas adsorption characteristics, including the different combinations of volume and pressure, of the samples taken from various Marcellus shale regions. Nevertheless, the general effect of adsorption-desorption is similar, i.e. it primarily increases gas production.

6. In the fractured vertical well configuration, the impact of desorption is marginal, i.e. a maximum of $2.7 \%$ increment in cumulative gas production is observed over 30 years in one of the adsorption cases of the Marcellus shale. Comparatively, around 2.35 times higher cumulative gas production is obtained through the single-stage multi-fractured horizontal well. This concludes that the desorption of gas requires a significant surface area and 
large fracture networks to contribute highly towards production.

Funding This research did not receive any specific grant from funding agencies in the public, commercial, or not-for-profit sectors.

\section{Declarations}

Conflict of interest The author declares that there is no conflict of interest.

Open Access This article is licensed under a Creative Commons Attribution 4.0 International License, which permits use, sharing, adaptation, distribution and reproduction in any medium or format, as long as you give appropriate credit to the original author(s) and the source, provide a link to the Creative Commons licence, and indicate if changes were made. The images or other third party material in this article are included in the article's Creative Commons licence, unless indicated otherwise in a credit line to the material. If material is not included in the article's Creative Commons licence and your intended use is not permitted by statutory regulation or exceeds the permitted use, you will need to obtain permission directly from the copyright holder. To view a copy of this licence, visit http://creativecommons.org/licenses/by/4.0/.

\section{References}

Ayers KL, Aminian K, Ameri S (2012) The impact of multistage fracturing on the production performance of the horizontal wells in shale formations. https://doi.org/10.2118/161347-MS

Bajus M (2014) Shale gas and tight oil, unconventional fossil fuels. Petrol Coal 56(3):206-221

Bartuska JE, Pechiney JJ, Leonard RS, Woodroof RA (2012) Optimizing completion designs for horizontal shale gas wells using completion diagnostics. https://doi.org/10.2118/155759-MS

Cipolla CL, Lolon E, Erdle JC, Rubin B (2009) Reservoir modeling in shale-gas reservoirs. https://doi.org/10.2118/125530-MS

EIA (2021) Drilling productivity report. https://www.eia.gov/petro leum/drilling/\#tabs-summary-1

El Sgher M, Aminian K, Ameri S (2018) Geomechanical impact on gas recovery from marcellus shale. https://doi.org/10.2118/ 190054-MS

El Sgher M, Aminian K, Ameri S (2021) Evaluation of hydraulic fracturing treatment with microseismic data analysis in a marcellus shale horizontal well. https://doi.org/10.2118/200877-MS

Eshkalak MO, Mohaghegh SD, Esmaili S (2013) Synthetic, geomechanical logs for marcellus shale. https://doi.org/10.2118/ 163690-MS

Eshkalak MO, Aybar U, Sepehrnoori K (2014) An integrated reservoir model for unconventional resources, coupling pressure dependent phenomena. https://doi.org/10.2118/171008-MS

Glorioso JC, Rattia A (2012) Unconventional reservoirs: basic petrophysical concepts for shale gas. https://doi.org/10.2118/ 153004-MS

Gomaa AM, Qu Q, Maharidge R, Nelson S, Reed T (2014) New insights into hydraulic fracturing of shale formations. https://doi. org/10.2523/IPTC-17594-MS

Holditch SA, Perry K, Lee J (2007) Unconventional gas reservoirstight gas, coal seams and shales. In: Working document of the national petroleum council on global oil and gas study, 52 .
Jia B, Li D, Tsau J-S, Barati R (2017) Gas permeability evolution during production in the marcellus and eagle ford shales: coupling diffusion/slip-flow, geomechanics, and adsorption/desorption. https://doi.org/10.15530/URTEC-2017-2695702

Lala AMS (2018) Modifications to the Kozeny-Carman model to enhance petrophysical relationships. Explor Geophys 49(4):553558. https://doi.org/10.1071/EG17015

Lin K, Huang X, Zhao YP (2020) Combining Image Recognition and Simulation to Reproduce the Adsorption/Desorption Behaviors of Shale Gas. Energy Fuels 34(1):258-269. https://doi.org/10.1021/ acs.energyfuels.9b03669

Lin K, Zhao YP (2021) Entropy and enthalpy changes during adsorption and displacement of shale gas. Energy. https://doi.org/10. 1016/j.energy.2021.119854

Memon A, Li A, Muther T, Ren X (2020) An experimental study of gas sorption, adsorbed, and sorbed porosity, and their impact on shale gas-in-place calculations. J Porous Media 23(10):985-1000

Memon A, Li A, Memon BS, Muther T, Han W, Kashif M, Tahir MU, Akbar I (2021) Gas adsorption and controlling factors of shale: review, application, comparison and challenges. Nat Resour Res 30(1):827-848

Mengal SA, Wattenbarger RA (2011) Accounting for adsorbed gas in shale gas reservoirs. https://doi.org/10.2118/141085-MS

Muther T, Khan MJ, Chachar MH, Aziz H (2020) A Study on designing appropriate hydraulic fracturing treatment with proper material selection and optimized fracture half-length in tight multilayered formation sequence. SN Applied Sciences. https://doi. org/10.1007/s42452-020-2729-9

Muther T, Nizamani AA, Ismail AR (2020) Analysis on the effect of different fracture geometries on the productivity of tight gas reservoirs. Malaysian J Fundam Appl Sci 16(2):201-211. https:// doi.org/10.11113/mjfas.v16n2.1343

Muther T, Syed FI, Dahaghi AK, Negahban S (2022) Socio-inspired multi-cohort intelligence and teaching-learning-based optimization for hydraulic fracturing parameters design in tight formations. J Energy Resources Technol. https://doi.org/10.1115/1. 4052182

Muther T, Syed FI, Dahaghi AK, Neghabhan S (2021) Subsurface physics inspired neural network to predict shale oil recovery under the influence of rock and fracture properties. In: 2021 International conference on innovations in intelligent systems and applications, INISTA 2021 - Proceedings. https://doi.org/ 10.1109/INISTA52262.2021.9548580

Seales MB, Dilmore R, Ertekin T, Wang JY (2016) A numerical study of factors affecting fracture-fluid cleanup and produced gas/water in marcellus shale: part II. SPE J 22(02):596-614. https://doi.org/10.2118/183632-PA

Sprunger C, Muther T, Syed FI, Dahaghi AK, Neghabhan S (2021) State of the art progress in hydraulic fracture modeling using AI/ML techniques. In: Modeling earth systems and environment. https://doi.org/10.1007/s40808-021-01111-w

Syed FI, Tunio AH, Ghirano NA (2011) Compositional Analysis and Screening for Enhanced Oil Recovery Processes in Different Reservoir and Operating Conditions. Int J Appl Sci Technol 1(4): $143-160$

Syed FI, AlShamsi A, Dahaghi AK, Neghabhan S (2020a) Application of ML and AI to model petrophysical and geo-mechanical properties of shale reservoirs - a systematic literature review. Petroleum

Syed FI, Alshamsi M, Dahaghi AK, Neghabhan S (2020b) Artificial lift system optimization using machine learning applications. Petroleum. https://doi.org/10.1016/j.petlm.2020.08.003

Syed FI, Alnaqbi S, Muther T, Dahaghi AK, Negahban S (2021a) Smart shale gas production performance analysis using machine learning applications. In: Petroleum research. https://doi.org/10. 1016/j.ptlrs.2021.06.003

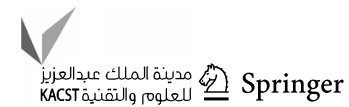


Syed FI, Muther T, Dahaghi AK, Negahban S (2021b) Low-rank tensors applications for dimensionality reduction of complex hydrocarbon reservoirs. Energy. https://doi.org/10.1016/j.energy.2021. 122680

Syed FI, Muther T, Dahaghi AK, Neghabhan S (2022) $\mathrm{CO}_{2}$ EOR performance evaluation in an unconventional reservoir through mechanistic constrained proxy modeling. Fuel 310:122390. https://doi. org/10.1016/j.fuel.2021.122390

Thompson JM., M'Angha VO, Anderson DM (2011) Advancements in shale gas production forecasting - a marcellus case study. https:// doi.org/10.2118/144436-MS

Tiab D, Donaldson EC (2016) Shale-gas reservoirs. Petrophysics. https://doi.org/10.1016/B978-0-12-803188-9.00012-7

Wang FP, Reed RM (2009) Pore networks and fluid flow in gas shales. https://doi.org/10.2118/124253-MS

Wang J, Song H, Rasouli V, Killough J (2019) An integrated approach for gas-water relative permeability determination in nanoscale porous media. J Petrol Sci Eng. https://doi.org/10.1016/j.petrol. 2018.10.017

Yildirim LT, Wang JY, Elsworth D (2019) Petrophysical evaluation of shale gas reservoirs: a field case study of marcellus shale. https:// doi.org/10.2118/197838-MS

Yu W, Sepehrnoori K (2013) Optimization of multiple hydraulically fractured horizontal wells in unconventional gas reservoirs. J Petrol Eng 2013:151898. https://doi.org/10.1155/2013/151898
Yu W, Sepehrnoori K (2014) Simulation of gas desorption and geomechanics effects for unconventional gas reservoirs. Fuel 116:455464. https://doi.org/10.1016/j.fuel.2013.08.032

Yu W, Sepehrnoori K (2014b) Sensitivity study and history matching and economic optimization for marcellus shale. https://doi.org/10. 15530/URTEC-2014-1923491

Yu W, Sepehrnoori K, Patzek TW (2016) Modeling gas adsorption in marcellus shale with langmuir and BET isotherms. SPE J 21(02):589-600. https://doi.org/10.2118/170801-PA

Yue M, Zhang Q, Zhu W, Zhang L, Song H, Li J (2020) Effects of proppant distribution in fracture networks on horizontal well performance. J Petrol Sci Eng. https://doi.org/10.1016/j.petrol.2019. 106816

Zhang Q, Zhu W, Liu W, Yue M, Song H (2020) Numerical simulation of fractured vertical well in low-permeable oil reservoir with proppant distribution in hydraulic fracture. J Petrol Sci Eng. https:// doi.org/10.1016/j.petrol.2020.107587

Zhang T, Sun S, Song H (2019) Flow mechanism and simulation approaches for shale gas reservoirs: a review. Transp Porous Med 126(3):655-681. https://doi.org/10.1007/s11242-018-1148-5

Publisher's Note Springer Nature remains neutral with regard to jurisdictional claims in published maps and institutional affiliations. 